\begin{tabular}{|c|c|}
\hline \multirow[t]{5}{*}{ Citation } & $\begin{array}{l}\text { Authors } \\
\text { Van Mileghem Seger, De Borggraeve Wim M. }\end{array}$ \\
\hline & $\begin{array}{l}2017 \\
\text { A convenient multigram synthesis of DABSO using sodium sulfite as } \mathrm{SO} 2 \\
\text { source }\end{array}$ \\
\hline & Journal \\
\hline & Organic Process Research \& Development \\
\hline & $\begin{array}{lll}\text { Volume:21 } & \text { Issue:5 } & \text { Pages:785-787 }\end{array}$ \\
\hline Archived version & Manuscript before formatting by journal \\
\hline Published version & http://dx.doi.org/10.1021/acs.oprd.7b00083 \\
\hline Journal homepage & http://pubs.acs.org/journal/oprdfk \\
\hline Author contact & $\begin{array}{l}\text { wim.deborggraeve@kuleuven.be } \\
+32(0) 16327693\end{array}$ \\
\hline IR & https://lirias.kuleuven.be/handle/123456789/588989 \\
\hline
\end{tabular}

(article begins on next page) 


\title{
A convenient multigram synthesis of DABSO using sodium sulfite as $\mathrm{SO}_{2}$ source
}

\author{
Seger Van Mileghem and Wim M. De Borggraeve* \\ Molecular Design and Synthesis, Department of Chemistry, KU Leuven, Celestijnenlaan 200F, box 2404, B-3001 Leuven, \\ Belgium \\ Supporting Information Placeholder
}

\begin{abstract}
A convenient synthesis of DABCO $\left(\mathrm{SO}_{2}\right)_{2}$ (abbreviated as DABSO) is reported. Using a two-chamber set-up, sulfur dioxide is generated in one chamber and consumed in the other. This closed system overcomes safety issues related to working with toxic $\mathrm{SO}_{2}$ gas. Pressure build-up is avoided by gradually generating the gas using sodium sulfite as precursor. Moreover, only nearstoichiometric amounts of $\mathrm{SO}_{2}$ are required for this protocol. The use of anhydrous solvents is not necessary and every step is performed at room temperature. A scale-up was carried out on a 10 gram scale which, after overnight drying, resulted in a quantitative yield.

KEYWORDS: DABSO, sulfur dioxide, two-chamber reactor, safety
\end{abstract}

\section{Introduction}

Sulfur dioxide is a ubiquitous commodity chemical which has several chemical applications in industrial processes. Until recently, it was not often used in an academic lab setting. ${ }^{1}$ This can partly be ascribed to the gaseous state of sulfur dioxide, as well as its notorious toxicity and smell. Considering the importance of functional groups such as sulfones and sulfonamides in agrochemicals, pharmaceuticals and materials, there is a high interest in new and enhanced synthesis methods. ${ }^{2}$ Therefore, the use of sulfur dioxide in synthetic organic chemistry is reviving. It is believed that the advancement of convenient and stable $\mathrm{SO}_{2}$ surrogates is an important driver in the rejuvenation of organic synthesis research involving $\mathrm{SO}_{2} .{ }^{3}$ The Willis group was the first to demonstrate the utility of DABCO $\left(\mathrm{SO}_{2}\right)_{2}$ (abbreviated as DABSO), a bench-stable solid reagent, as a sulfur dioxide equivalent in the synthesis of $\mathrm{N}$-aminosulfonamides, sulfonamides and sulfamides. ${ }^{4}$ Since then, numerous synthetic studies using DABSO as $\mathrm{SO}_{2}$ equivalent have been published. ${ }^{5}$ Moreover, in some cases the use of DABSO was more successful than using $\mathrm{SO}_{2}$ gas, presumably due to catalyst poisoning by the excess sulfur dioxide..$^{5 a}$

Since DABSO is a relative expensive chemical, some research groups synthesize it on site. ${ }^{4 \mathrm{~b}, 6}$ These procedures include the use of sulfur dioxide gas, implying safety considerations regarding the handling and storage of sulfur dioxide pressurized vessels and using a large excess of the gas. Usually DABSO precipitates out of solution when formed. The Bischoff group circumvented the use of $\mathrm{SO}_{2}$ vessels by synthesizing DABSO with the commercially available Karl-Fischer reagent. ${ }^{7}$ However, since this reagent is a solution of a base (usually pyridine) and an alcohol (usually methanol) containing $15-20 \%$ of $\mathrm{SO}_{2}$, this protocol leads to more complex mixtures and a low atom economy. Moreover, DABSO is soluble in methanol, resulting in a less efficient precipitation. To the best of our knowledge, no protocol for the syn- thesis of DABSO is reported where $\mathrm{SO}_{2}$ is generated in a controlled fashion and consumed in a closed system, omitting multiple safety issues of working with this toxic gas.

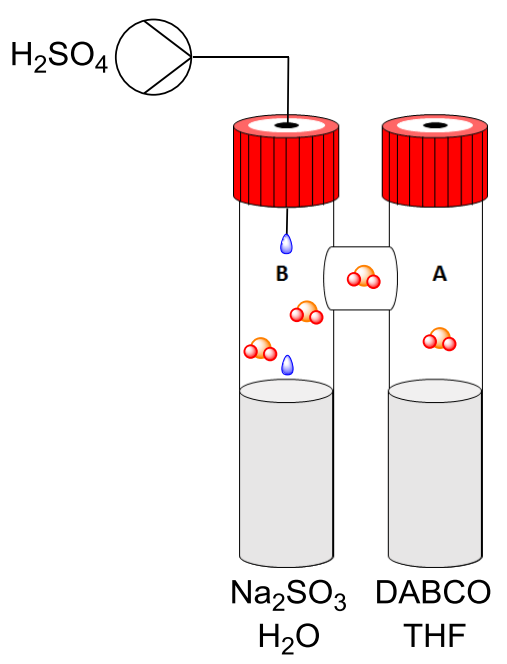

Figure 1: Reaction set-up. $\mathrm{SO}_{2}$ is gradually generated in chamber $B$ and is consumed in chamber $A$ to form DABSO.

\section{Results and discussion}

Here we report a convenient multigram synthesis of DABSO. By making use of the elegant two-chamber system (COware) reported by Skrydstrup et al. ${ }^{8}$ it is possible to generate and consume sulfur dioxide $e x$ situ. Previous success with these reactors for $e x$ situ gas generation in our group motivated us to pursue this route. ${ }^{9}$ The reaction set-up is depicted in Figure 1 and the results are summarized in Table 1. Metal sulfite salts are known to release $\mathrm{SO}_{2}$ when reacting with strong acids. ${ }^{10}$ Moreover, the use of sodium sulfite as an $\mathrm{SO}_{2}$ surrogate has been applied in palladium-catalyzed aminosulfonylation. ${ }^{11}$ Due to its simplicity and 
cheap nature, this was our $\mathrm{SO}_{2}$ surrogate of choice. Since the release of $\mathrm{SO}_{2}$ from sodium sulfite and strong acid is fast, ${ }^{10}$ a gradual release is preferred to avoid generating high pressure in the reactor. Furthermore, sulfur dioxide is far more soluble in water and organic solvents than other gases used in synthesis (e.g. CO and $\left.\mathrm{H}_{2}\right) .{ }^{12}$ Therefore, sodium sulfite is solubilized in water, and sulfuric acid is slowly added by means of a syringe pump, resulting in a gradual release of $\mathrm{SO}_{2}$.

In a first trial, DABCO (673 mg, $6 \mathrm{mmol})$ was added in THF $(8 \mathrm{~mL})$ in chamber A while 2.5 equivalents $(1.89 \mathrm{~g})$ of sodium sulfite were added in water in chamber B (Table 1, entry a). Next, sulfuric acid $(960 \mu \mathrm{L}, 3$ equivalents) was added dropwise over 10 minutes to chamber B. After 15 minutes, a white precipitate was observed, indicating DABSO formation. After 2 hours of stirring at room temperature, filtration and overnight drying, DABSO was obtained in a yield of $94 \%$. (It should be noted that the overnight drying was performed either on a Schlenk line or in a desiccator. When drying under high vacuum (lyophilizer), a lot of product was evaporated due to volatility!) To make sure no other impurities were precipitating in chamber A, a blank reaction was performed without the use of sodium sulfite (entry b). No precipitate was formed in chamber A. Using a lower excess of both sodium sulfite and sulfuric resulted in a nearly identical yield (entry c). At this stage, it was desirable to perform this reaction at a larger scale. Therefore, the flow rate of sulfuric acid was lowered to $50 \mu \mathrm{L} \mathrm{min}{ }^{-1}$ to avoid pressure build-up and the reaction was stirred overnight. A first scale-up resulted in a disappointing yield of $63 \%$ (entry d). It was hypothesized that this result could be attributed to increasing the molarity of DABCO in THF. After stirring overnight, DABSO was precipitated and barely any THF was visible. This could have led to a physical barrier (DABSO matrix) between the remaining DABCO and $\mathrm{SO}_{2}$. To our delight, when more THF was used, this issue was resolved and a quantitative yield was obtained (entry e). During this run the pressure inside the reactor was monitored via a manometer and it never exceeded 2 bar. This confirms there is a gradual release and consumption of $\mathrm{SO}_{2}$ gas. Since first signs of precipitation of DABSO are apparent after about 2 hours of reaction (See Supplementary Video), an attempt to decrease the reaction time was tested (entry f). A disappointing yield of $53 \%$ was obtained and hence more time is needed to bring the reaction to completion. As it appears, this procedure is about 2.5 times more cost efficient than the procedure reported by Bischoff $e t a l$. and about 27 times cheaper than commercially available DABSO. ${ }^{7 b}$ (A price comparison can be found in the Supporting Information.)

\section{Conclusion}

We have developed a convenient multigram synthesis of DABSO. Sulfur dioxide is generated and consumed in a closed two-chamber system, hereby avoiding a lot of safety issues of working with the toxic gas. The danger of pressure build-up is avoided by gradually releasing $\mathrm{SO}_{2}$. No heating or cooling is required, nor is working with anhydrous solvents. High to quantitative yields are obtained. This protocol is suited for synthesizing DABSO on a $10 \mathrm{~g}$ scale.
Table 1: Results of two-chamber synthesis of DABSO. ${ }^{a}$

\begin{tabular}{|c|c|c|c|c|c|c|c|c|}
\hline \multirow[b]{2}{*}{ Entry } & & & & $\begin{array}{c}\mathrm{Ia}_{2} \mathrm{SO}_{3} \\
\mathrm{H}_{2} \mathrm{SO}_{4} \\
{\left[\mathrm{SO}_{2}\right]}\end{array}$ & $\begin{array}{l}0_{i s} \Theta_{0} \\
i^{1}{ }^{N}\end{array}$ & \multirow[b]{2}{*}{$\begin{array}{c}\text { eq } \\
\mathrm{Na}_{2} \mathrm{SO}_{3}\end{array}$} & \multirow[b]{2}{*}{$\mathrm{t}(\mathrm{h})$} & \multirow[b]{2}{*}{$\begin{array}{l}\text { Yield } \\
(\%)\end{array}$} \\
\hline & $\begin{array}{c}\text { mmol } \\
\text { DABCO }\end{array}$ & $\begin{array}{l}\mathrm{V}_{\mathrm{THF}} \\
(\mathrm{mL})\end{array}$ & $\begin{array}{l}\mathrm{V}_{\mathrm{H}_{2} \mathrm{O}} \\
(\mathrm{mL})\end{array}$ & $\begin{array}{c}\mathrm{V}_{\mathrm{H}_{2} \mathrm{SO}_{4}} \\
(\mu \mathrm{L} / \mathrm{min})\end{array}$ & $\begin{array}{c}\mathrm{V}_{\mathrm{H}_{2} \mathrm{SO}_{4}} \\
(\mu \mathrm{L})\end{array}$ & & & \\
\hline $\mathbf{a}$ & 6 & 8 & 8 & 100 & 960 & 2.5 & 2 & 94 \\
\hline b & 6 & 8 & 8 & 100 & 960 & 0 & 2 & 0 \\
\hline c & 6 & 8 & 8 & 100 & 800 & 2.2 & 2 & 92 \\
\hline d & 45 & 30 & 25 & 50 & 6000 & 2.2 & $\mathrm{ON}$ & 63 \\
\hline e & 45 & 60 & 40 & 50 & 6000 & 2.2 & $\mathrm{ON}$ & 99 \\
\hline f & 45 & 60 & 40 & 50 & 6000 & 2.2 & 3 & 53 \\
\hline
\end{tabular}

\section{Experimental section}

For ${ }^{1} \mathrm{H}-\mathrm{NMR}$, a Bruker 300 Avance (300 MHz), a Bruker 400 Avance $(400 \mathrm{MHz})$ and a Bruker 600 Avance II+ (600 MHz) with tetramethylsilane as internal standard with $\mathrm{CDCl}_{3}$ and DMSO were used. The $\delta$-values are expressed in ppm. For ${ }^{13} \mathrm{C}$ NMR, a Bruker 300 Avance (operating at $75 \mathrm{MHz}$ ), a Bruker 400 Avance (operating at $100 \mathrm{MHz}$ ) and a Bruker 600 Avance II+ (operating at $150 \mathrm{MHz}$ ) with the deuterated solvent as internal standard was used $\left(\mathrm{CDCl}_{3}\right.$ : $77.2 \mathrm{ppm}$, triplet; DMSO: 39.52 ppm, quintet). The $\delta$-values are expressed in ppm. Elemental analysis (CHN) was carried out on a Thermo Scientific Flash 2000 Organic Elemental Analyzer. For melting point, a Reichert-Jung Thermovar was used. All reagents were used as purchased without further purification. DABCO (98\%) was purchased from Sigma-Aldrich. THF $(>99.9 \%$, spiked with BHT as inhibitor) was purchased from Honeywell. Sodium sulfite was purchased from Sigma-Aldrich. Diethyl ether $(>99 \%$, spiked with BHT as inhibitor) was purchased from ChemLab. Sulfuric acid (>95\%) was purchased from Fisher Scientific.

Procedure for the synthesis of 1,4-diazabicyclo[2.2.2] octane bis(sulfur dioxide) (DABSO)

A symmetrical two-chamber reactor (inner volume $=400 \mathrm{~mL}$ ) is charged with a Teflon-coated oval stirring bar in each chamber. $5.050 \mathrm{~g}$ of DABCO (45 mmol) is added in chamber A and $12.480 \mathrm{~g}$ of $\mathrm{Na}_{2} \mathrm{SO}_{3}$ (99 mmol, 2.2 equivalents) is added in chamber B. Two screw caps with septa are fitted on the reactor and air is evacuated and back-filled with nitrogen. This process is repeated three times. THF $(60 \mathrm{~mL})$ is added via a syringe in chamber A and similarly water $(40 \mathrm{~mL})$ is added in chamber B under a positive pressure by means of a nitrogen balloon. After 10 minutes of stirring at room temperature, the balloon is removed and $\mathrm{H}_{2} \mathrm{SO}_{4}(6 \mathrm{~mL})$ is gradually added via a syringe pump

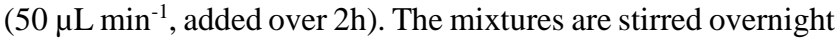
at room temperature. After this, the solution in chamber B is removed and the suspension in chamber $\mathrm{A}$ is transferred to a $100 \mathrm{~mL}$ sintered-glass funnel under reduced pressure. The white solid is washed five times with $50 \mathrm{~mL}$ of diethyl ether. DABSO is known to be hygroscopic and therefore, it is transferred to a flask and dried in a desiccator under vacuum overnight to afford the product as a white powder $(10.75 \mathrm{~g}, 99 \%)$. It should be noted that DABSO is usually referred to as a benchstable solid in literature, while most groups (including our 
group) store it in a freezer or fridge, which is also recommended by commercial suppliers. A video recording of the synthetic procedure can be found in the Supporting Information. Analytical properties of DABSO prepared in this way are in agreement with the literature. ${ }^{7 \mathrm{~b}} \mathrm{mp} 141-143{ }^{\circ} \mathrm{C} ;{ }^{1} \mathrm{H}$ NMR $(400 \mathrm{MHz}$, $\left.\mathrm{CD}_{3} \mathrm{OD}\right): \delta 3.22$ (s); ${ }^{13} \mathrm{C}$ NMR (100 MHz, CD $\left.{ }_{3} \mathrm{OD}\right): \delta 45.4$; Anal calcd: C 29.99, H 5.03, N 11.66; found C 30.38, H 5.24, N 11.60.

\section{Corresponding author}

* E-mail: wim.deborggraeve@kuleuven.be

\section{ORCID}

Wim De Borggraeve: 0000-0001-7813-6192

Seger Van Mileghem: 0000-0003-0802-2995

\section{Notes}

The authors declare no competing financial interest.

\section{Acknowledgement}

We would like to thank KU Leuven for financial support via project OT/14/067.

\section{Supporting Information Available.}

Experimental procedures, characterization data and copies of spectra and a video of this protocol are available free for charge via the Internet at http://pubs.acs.org.

\section{References}

1. Müller, H., Ullmann's Encyclopedia of Industrial Chemistry. Wiley-VCH: Weinheim, 2000.

2. Liu, G.; Fan, C. B.; Wu, J., Org. Biomol. Chem., 2015, 13 (6), 1592-1599.

3. Deeming, A. S.; Emmett, E. J.; Richards-Taylor, C. S.; Willis, M. C., Synthesis, 2014, 46 (20), 2701-2710.

4. (a) Woolven, H.; Gonzalez-Rodriguez, C.; Marco, I.; Thompson, A. L.; Willis, M. C., Org. Lett., 2011, 13 (18), 48764878; (b) Nguyen, B.; Emmett, E. J.; Willis, M. C., J. Am. Chem. Soc., 2010, 132 (46), 16372-16373.

5. Some examples: (a) Emmett, E. J.; Richards-Taylor, C. S.; Nguyen, B.; Garcia-Rubia, A.; Hayter, B. R.; Willis, M. C., Org. Biomol. Chem., 2012, 10 (20), 4007-4014; (b) Richards-Taylor, C. S.; Blakemore, D. C.; Willis, M. C., Chem. Sci., 2014, 5 (1), 222-228; (c) Tsai, A. S.; Curto, J. M.; Rocke, B. N.; Dechert-Schmitt, A. M. R.; Ingle, G. K.; Mascitti, V., Org. Lett., 2016, 18 (3), 508-511; (d) Zheng, D. Q.; An, Y. Y.; Li, Z. H.; Wu, J., Angew. Chem. Int. Ed., 2014, 53 (9), 24512454; (e) Deeming, A. S.; Russell, C. J.; Willis, M. C., Angew. Chem. Int. Ed., 2016, 55 (2), 747-750; (f) Rocke, B. N.; Bahnck, K. B.; Herr, M.; Lavergne, S.; Mascitti, V.; Perreault, C.; Polivkova, J.; Shavnya, A., Org. Lett., 2014, 16 (1), 154-157.

6. (a) Santos, P. S.; Mello, M. T. S., J. Mol. Struct., 1988, 178, 121-133; (b) Mouselmani, R.; Da Silva, E.; Lemaire, M., Tetrahedron, 2015, 71 (47), 8905-8910.

$7 . \quad$ (a) Martial, L.; Bischoff, L., Synlett, 2015, 26 (9), 1225-1229; (b) Martial, L.; Bischoff, L., Org. Syn., 2013, 90, 301-305.

8. $\quad$ (a) Hermange, P.; Lindhardt, A. T.; Taaning, R. H.; Bjerglund, K.; Lupp, D.; Skrydstrup, T., J. Am. Chem. Soc.,
2011, 133 (15), 6061-6071; (b) Friis, S. D.; Taaning, R. H.; Lindhardt, A. T.; Skrydstrup, T., J. Am. Chem. Soc., 2011, 133 (45), 18114-18117.

9. $\quad$ Veryser, C.; Van Mileghem, S.; Egle, B.; Gilles, P.; De Borggraeve, W. M., React. Chem. Eng., 2016, 1 (2), 142146.

10. Emmett, E. J.; Willis, M. C., Asian J. Org. Chem., 2015, 4 (7), 602-611.

11. Li, W. F.; Li, H. Q.; Langer, P.; Beller, M.; Wu, X. F., Eur. J. Org. Chem., 2014, 2014 (15), 3101-3103.

12. (a) Li, H.; Jiao, X. L.; Chen, W. R., Phys. Chem. Liq., 2014, 52 (2), 349-353; (b) van Dam, M. H. H.; Lamine, A. S.; Roizard, D.; Lochon, P.; Roizard, C., Ind. Eng. Chem. Res., 1997, 36 (11), 4628-4637; (c) Spedding, D. J.; Brimblecombe, P., Atmos. Environ., 1974, 8 (10), 1063-1063. 